\title{
Renal Nerve Deafferentation Attenuates the Fall in GFR during Intravenous Infusion of Furosemide in Anesthetized Rats
}

\author{
Magali Araujo Glenn Solis William J. Welch Christopher S. Wilcox \\ Hypertension Research Center and Division of Nephrology and Hypertension, Georgetown \\ University, Washington, DC, USA
}

\author{
Keywords \\ Volume replacement · Loop diuretic · Renal nerves · Renal vascular resistance · Angiotensin \\ receptor blocker
}

\begin{abstract}
Introduction: Furosemide reduces the glomerular filtration rate (GFR) and increases the renal vascular resistance (RVR) despite inhibiting tubuloglomerular feedback but increases proximal tubule pressure, renin release, and renal nerve activity. Objective: This study tested the hypothesis that the fall in GFR with furosemide is due to volume depletion or activation of angiotensin type 1 (AT1) receptors or renal nerves. Methods: Furosemide was infused for 60 min at $1.0 \mathrm{mg} \cdot \mathrm{kg}^{-1} \cdot \mathrm{h}^{-1}$ in groups of 5-8 anesthetized rats. Additional groups received intravenous volume replacement to prevent fluid and $\mathrm{Na}^{+}$losses or volume replacement plus losartan or plus sham denervation or plus renal denervation or renal nerve deafferentation. Results: At 60 min of infusion, furosemide alone reduced the GFR $(-37 \pm 4 \% ; p<0.01)$. This fall was not prevented by volume replacement or pretreatment with losartan, although losartan moderated the increase in RVR with furosemide (+44 \pm 3 vs. $+82 \pm 7 \% ; p<0.01)$. Whereas the GFR fell after furosemide in rats after sham procedure $(-31 \pm 2 \%)$, it was not changed significantly after prior renal deafferentation. Proximal tubule pressure increased significantly but returned towards baseline over 60 min of furosemide, while urine output remained elevated, and GFR and renal blood flow depressed. Conclusions: The fall in GFR over 60 min of furosemide infusion is independent of volume depletion or activation of AT1 receptors but is largely dependent on renal afferent nerves.




\section{Kidney \\ Blood Pressure \\ Research}

\begin{tabular}{l|l}
\hline Kidney Blood Press Res 2020;45:70-83 \\
\hline DOI: 10.1159/000504223 & $\begin{array}{l}\text { @ 2020 The Author(s). Published by S. Karger AG, Basel } \\
\text { www.karger.com/kbr }\end{array}$ \\
\hline
\end{tabular}

Araujo et al.: Furosemide and GFR

\section{Introduction}

Furosemide is prescribed widely for patients with edema or hypertension. It inhibits the $\mathrm{Na}^{+}-\mathrm{K}^{+}-2 \mathrm{Cl}^{-}$cotransporter (NKCC2) in the thick ascending limb of the loop of Henle to cause a potent natriuresis and diuresis. However, furosemide reduces the glomerular filtration rate (GFR) and renal blood flow (RBF) and increases the renal vascular resistance (RVR) of anesthetized rats, despite inhibition of tubuloglomerular feedback (TGF) that should cause renal vasodilatation [1]. The fall in GFR with furosemide in human subjects [2-5] is poorly understood [6] but is a major concern in the treatment of edema and congestion [7]. Studies in mice have suggested that the fall in GFR with loop diuretics is related to blood volume depletion, activation of the renin-angiotensin system (RAS), or increases in the intratubular or interstitial pressures, but their relative importance is not clear [8].

Both the afferent and efferent renal nerves can regulate renal hemodynamics in animals and in humans [9-11]. Renal efferent sympathetic nerve activity contributes to hypertension [12] and can increase sodium reabsorption and renal angiotensin II [13] and reduce the GFR and RBF depending on the intensity of renal nerve activation [14]. Renal afferent nerve activity regulates blood pressure [15], renal efferent nerve activity, and renal function via a renorenal reflex [16]. The renal afferent nerves contribute to progressive renal damage in a rat model of chronic kidney disease (CKD) and high salt intake [16] and to hypertension and vasoconstriction in patients with CKD [17]. Reflex activation of renal efferent nerves accompanies a fall in central venous pressure as can occur with loop diuretics [18]. Afferent renal nerves are activated by renal mechanoreceptors in response to a rise in hydrostatic pressure and renal chemoreceptors in response to a rise in salt intake $[16,19]$.

A single dose of furosemide given to normal human subjects decreases their GFR by $\sim 23 \%$ [5], increases the plasma angiotensin II by $>150 \%$, the plasma norepinephrine by $40-60 \%[3,4]$, and the heart rate by $15 \%$ and decreases the plasma volume by $\sim 10 \%[3,4$, $20]$. Thus, although furosemide blocks the TGF that should increase the GFR, it activates the RAS and the sympathetic nervous system and reduces the blood volume that should reduce the GFR [1]. The mechanism responsible for the hemodynamic effects of furosemide remains largely unclear [6]. Accordingly, we tested the hypothesis that the change in GFR during a 1-h infusion of furosemide was due to volume depletion or to activation of angiotensin type 1 (AT1) receptors or renal nerve activity. Inhibition of tubular fluid reabsorption will raise intratubular pressure that might physically curtail the GFR. This was assessed from free flow micropuncture measurements of the hydrostatic pressure in the proximal tubule $\left(\mathrm{P}_{\mathrm{PT}}\right)$.

\section{Materials and Methods}

Male Sprague-Dawley rats weighing 250-300 g were maintained on a standard rat chow $\left(0.3 \mathrm{~g} \cdot 100 \mathrm{~g}^{-1} \mathrm{Na}^{+}\right.$content) with free access to food and water until the day of the study. The use of animals was approved by the Georgetown University Animal Care and Use Committee and performed according to the National Institutes of Health guidelines for the conduct of experiments in animals. On the day of the study, rats were anesthetized with Inactin $(50 \mathrm{mg} /$ kg body weight (BW $)^{-1}$, i.p.; Research Biochemicals). Other rats were prepared for renal clearance and micropuncture, as previously described $[1,21]$. The left kidney was placed in a Lucite cup. Rats received an i.v. infusion of $1 \%$ bovine serum albumin (Sigma) at $0.3 \mathrm{~mL} \cdot 100$ $\mathrm{g} \mathrm{BW}^{-1} \cdot \mathrm{h}^{-1}$ to which was added $\left[{ }^{3} \mathrm{H}\right]$ inulin and $\left[{ }^{14} \mathrm{C}\right]$ para-aminohippurate $(\mathrm{PAH})$ to estimate the GFR and effective renal plasma flow. After stabilization, urine was collected for $20 \mathrm{~min}$ during infusion of vehicle (saline) and for three 20-min periods during constant infusions of furosemide at $1.0 \mathrm{mg} \cdot \mathrm{kg} \mathrm{BW}^{-1} \cdot \mathrm{h}^{-1}$. Plasma samples and hematocrit were obtained from the 


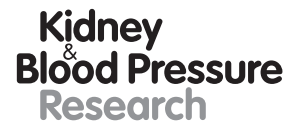

Research \begin{tabular}{l|l}
\hline Kidney Blood Press Res 2020:45:70-83 \\
\hline DOI: 10.1159/000504223 & $\begin{array}{l}\text { @ 2020 The Author(s). Published by S. Karger AG, Basel } \\
\text { www.karger.com/kbr }\end{array}$ \\
\hline
\end{tabular}

Araujo et al.: Furosemide and GFR

femoral artery at the midpoint of each urine collection. Hydrostatic pressure in the proximal tubule $\left(\mathrm{P}_{\mathrm{PT}}\right)$ was measured by micropuncture using free-flow conditions during 3 min before and during the infusion of furosemide, as previously described [1]. An average of three nephrons per period was recorded and the values averaged.

\section{Study Design}

Series 1: Effects of Volume Depletion and AT1 Receptor Activation

Three groups of rats were studied: group 1 - furosemide $\left(1.0 \mathrm{mg} \cdot \mathrm{kg} \mathrm{BW}^{-1} \cdot \mathrm{h}^{-1} \times 1 \mathrm{~h} ;[n=\right.$ 8]); group 2 - furosemide + volume replacement: furosemide $\left(1.0 \mathrm{mg} \cdot \mathrm{kg} \mathrm{BW} \cdot \mathrm{h}^{-1} \times 1 \mathrm{~h}\right)$ while continuously replacing urine losses with a variable infusion of isotonic Ringer solution $(\mathrm{NaCl}$ $154 \mathrm{~mm}, \mathrm{KCl} 5.6 \mathrm{~mm}, \mathrm{CaCl}_{2} 2.2 \mathrm{~mm}, \mathrm{NaHCO}_{3} 25 \mathrm{~mm}, \mathrm{pH} 7.4$ ) at rates to match urine output $(n=7)$; group 3 - furosemide + volume replacement + losartan: furosemide $(1.0 \mathrm{mg} / \mathrm{kg}$ $\left.\mathrm{BW}^{-1} \cdot \mathrm{h}^{-1} \times 1 \mathrm{~h}\right)$ while replacing urine losses after i.v. administration of losartan $(10 \mathrm{mg} / \mathrm{kg}$ $\left.\mathrm{BW}^{-1}\right)$ immediately before furosemide $(n=7)$.

Because GFR and RBF were slightly elevated in the first 20 min of clearance experiments, a study of RBF was undertaken in 6 rats with a transit time blood flow probe around the left renal artery [22]. Mean arterial pressure (MAP) was measured continuously through a femoral catheter connected to an electrically damped output of a pressure transducer (Powerlab system, AD Instruments). These rats were given 30 min to recover from surgery and infused for 30 min with furosemide i.v. to study the initial changes in RBF and RVR.

Series 2: Effects of Renal Denervation and Renal Nerve Deafferentation

Three groups of rats underwent survival surgeries 10 days before study. Rats were anesthetized with $2 \%$ isoflurane. The abdomen was shaved and disinfected with a povidone iodine prep pad. A midline abdominal incision was made, and the fat surrounding the renal artery and vein was dissected gently away from the vessels to expose the renal nerves. After each procedure, the incision was closed; the rats received a subcutaneous injection of buprenorphine $(0.05-0.1 \mathrm{mg} / \mathrm{kg}$ ) and were observed for $1 \mathrm{~h}$ before returning to the animal facility. Group 4 - sham-operated rats: these rats underwent a bilateral approach to the kidneys but without renal nerve transection $(n=6)$; group 5 - renal denervation: all visible renal nerves were stripped from both renal arteries, and both renal arteries were painted with $10 \%$ phenol in ethanol $(n=6)$; group 6 - renal nerve deafferentation: after the dissection of the renal vein and artery, a small piece of gauze soaked in capsaicin solution (capsaicin, $33 \mathrm{~mm}$ in 5\% ethanol, $5 \%$ Tween 80 , and $90 \%$ normal saline) was wrapped around each renal artery for 15 min for selective ablation of renal afferent nerves $(n=8)$. Renal nerve deafferentation has been shown to drastically decrease renal pelvic content of the afferent nerve marker CGRP, while renal denervation decreased the efferent nerve marker norepinephrine [23, 24]. On the day of the experiment, each rat received furosemide $\left(1.0 \mathrm{mg} \cdot \mathrm{kg} \mathrm{BW}^{-1} \cdot \mathrm{h}^{-1} \times 1 \mathrm{~h}\right)$ while replacing urine volume losses as in groups 2 and 3.

\section{Statistics}

Comparison of results after furosemide among different groups used one-way ANOVA and Turkey multiple comparison tests. Repeated measures one-way ANOVA and Dunnett's multiple comparison tests were used to compare the time course of effects of furosemide with baseline (vehicle) in each group. Results are presented as mean \pm SE. A $p$ value $\leq 0.05$ was considered statistically significant. 
Fig. 1. Mean $\pm S E$ values for mean arterial pressure, renal blood flow measured by a flowmeter, and renal vascular resistance before ( -10 to $0 \mathrm{~min}$ ) and during 20 min of furosemide infusion. Compared to before: ${ }^{*} p<0.05$; ${ }^{* *} p<$ 0.01 ; $^{* *} p<0.005$ ( $n=6$ rats).
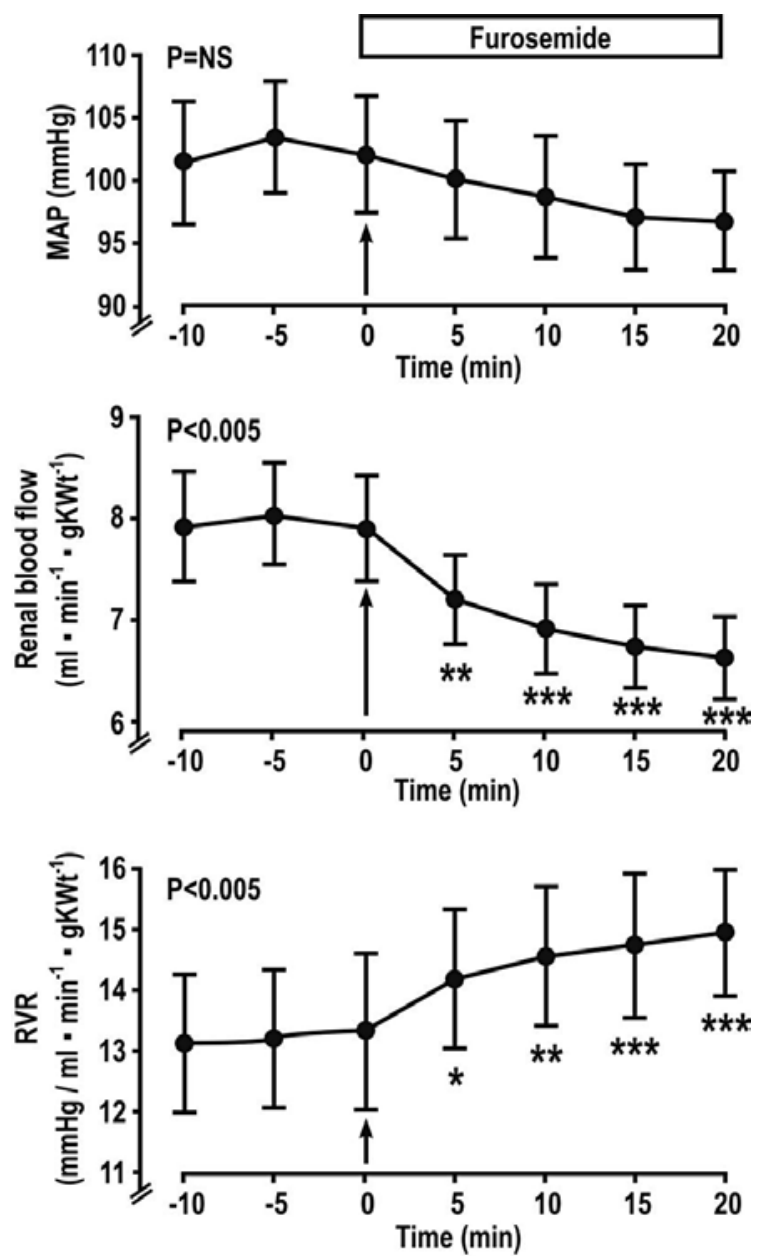

\section{Results}

Short-Term Effects of Furosemide on RBF and RVR Studied by Transit Time Flowmetry

Within 5 min of starting the furosemide infusion, the RBF was reduced and the RVR increased. These changes increased over the 20 min of furosemide infusion (Fig. 1).

\section{Effects of Furosemide Alone or during Volume Replacement or AT1 Receptor Blockade}

After $60 \mathrm{~min}$ of furosemide infusion, there were similar fractional reductions in GFR and RBF of circa $40 \%$ after furosemide alone or with volume replacement or losartan (Fig. 2A, B). RVR increased by $82 \pm 7 \%$ with furosemide and by $92 \pm 10 \%$ with furosemide plus volume replacement (NS) but only by $44 \pm 3 \%$ with furosemide after the losartan $(p<0.01$; Fig. 2 C) because of a similar fall in RBF with losartan despite a fall in MAP ( $p<0.01 ;$ Fig. 2D). The urine output (UV) after $60 \mathrm{~min}$ of i.v. infusion of furosemide was similar in the three groups with volume replacement (Fig. 2E), whereas the hydrostatic pressure in the proximal tubule $\left(\mathrm{P}_{\mathrm{PT}}\right)$ after 60 min was significantly increased only in rats that received losartan $(p<0.01$; Fig. 2F). There were no changes in heart rate or hematocrit, but the filtration fraction was reduced after losartan (Table 1). The time course of the absolute values for renal function and hemodynamics before and during furosemide in groups 1-3 are shown in Figure 3. The GFR and RBF fell significantly and the RVR increased progressively in all groups after 40 and $60 \mathrm{~min}$ following 


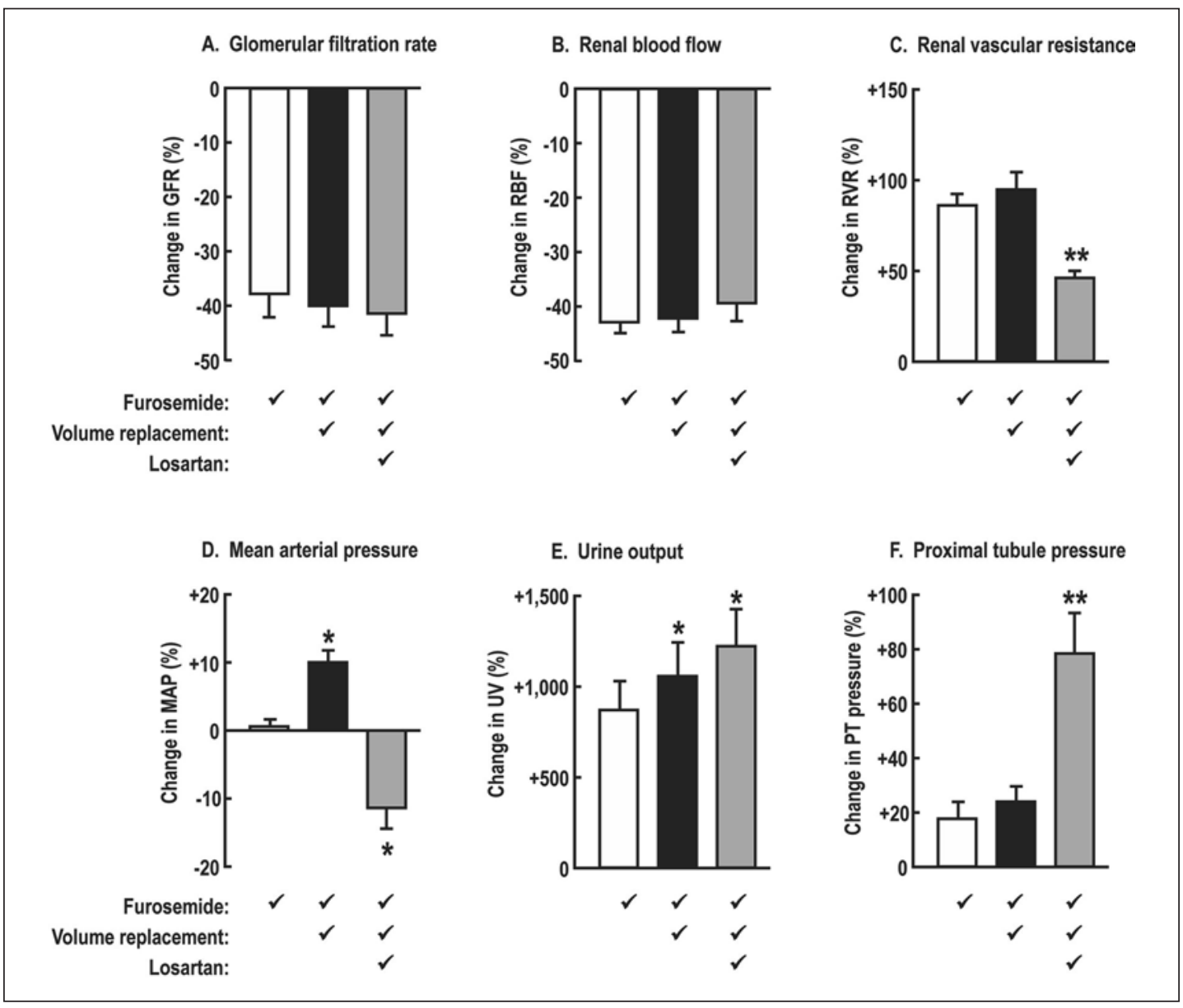

Fig. 2. Mean $\pm S E$ values for fractional changes in renal hemodynamics, mean arterial pressure, urine output, and proximal tubule pressure after $60 \mathrm{~min}$ of a constant systemic infusion of furosemide (open bars, $n=8$ ), furosemide with volume replacement (solid bars, $n=7$ ), and furosemide with volume replacement and losartan (grey bars, $n=7$ ). Compared to furosemide alone: * $p<0.05$, ${ }^{* *} p<0.01$.

furosemide infusion (** $p<0.01$ vs. vehicle; Fig. 3A-C). The MAP was quite well maintained except after losartan, where it fell progressively $\left({ }^{*} p<0.05\right.$ vs. vehicle; Fig. 3D). The UV increased more in the two groups with volume replacement than after furosemide alone $\left({ }^{* *} p<0.01\right.$ vs. vehicle; Fig. 3E). The hydrostatic pressure in the proximal tubule was elevated after $20 \mathrm{~min}$ in all groups (** $p<0.01 \mathrm{vs}$. vehicle) but fell progressively after $40 \mathrm{~min}$, except in the losartan group (** $p<0.01$ vs. vehicle; Fig. 3F).

\section{Effects of Furosemide and Volume Replacement after Sham Procedures, Renal}

\section{Denervation, and Renal Nerve Deafferentation}

After 60 min of furosemide infusion with volume replacement, the GFR of rats with sham procedures or renal denervation was reduced by $31 \pm 3$ and $27 \pm 6 \%$, respectively, but in rats with renal nerve deafferentation the GFR was reduced by only $13 \pm 8 \%(p<0.05$ vs. other groups; Fig. 4A). There were no significant differences in the fall in RBF with furosemide in these groups (Fig. 4B) but the RVR after furosemide increased less in the group with renal deafferentation ( $p<0.05$; Fig. 4C). The UV and the $\mathrm{P}_{\mathrm{PT}}$ increased similarly after furosemide in all three groups (Fig. 4E, F). There were no changes in heart rate or hematocrit but the filtration fraction increased in each group (Table 2). 
Table 1. Heart rate, hematocrit, and filtration fraction of rats during infusion of Veh and after 20-min periods of intravenous infusion of F, F/VR, or F/VR/Los

\begin{tabular}{lccc}
\hline & F & F/VR & F/VR/Los \\
\hline Heart rate, bpm & & & \\
Veh & $359 \pm 14$ & $350 \pm 37$ & $350 \pm 17$ \\
20 min & $359 \pm 15$ & $368 \pm 40$ & $355 \pm 16$ \\
40 min & $350 \pm 15$ & $379 \pm 41$ & $342 \pm 14$ \\
60 min & $340 \pm 17$ & $371 \pm 37$ & $335 \pm 14$ \\
\hline Hematocrit, \% & & \\
Veh & $46 \pm 1$ & $44 \pm 2$ & $48 \pm 2$ \\
60 min & $46 \pm 1$ & $44 \pm 2$ & $46 \pm 2$ \\
\hline Filtration fraction & & & \\
Veh & $0.49 \pm 0.03$ & $0.42 \pm 0.02$ & $0.51 \pm 0.03$ \\
20 min & $0.51 \pm 0.03$ & $0.40 \pm 0.02$ & $0.47 \pm 0.02$ \\
40 min & $0.55 \pm 0.04$ & $0.41 \pm 0.03$ & $0.45 \pm 0.03$ \\
60 min & $0.55 \pm 0.04$ & $0.43 \pm 0.03$ & $0.44 \pm 0.03^{*}$ \\
\hline
\end{tabular}

Values are mean \pm SE ( $n=5-8$ per group). Veh, vehicle (before); F, furosemide; F/VR, furosemide plus volume replacement; F/VR/Los, furosemide plus volume replacement plus losartan; 20, 40, 60 min, time into furosemide infusion. ${ }^{*} p<0.05$ vs. baseline (Veh).

The time course of changes in the absolute values for renal function and hemodynamics during furosemide and volume replacement are shown in Figure 5. The GFR and RBF rose and the RVR fell in all groups after 20 min of furosemide (Fig. 5A-C). While the RBF decreased significantly in all groups after $60 \mathrm{~min}$, a significant decrease in GFR was observed only in the sham group at 60 min, compared to its baseline (vehicle) (Fig. 5A, B). The RVR increased similarly in all three groups after 40-60 min (Fig. 5C). The UV increased significantly over this time in all groups, especially in the group with deafferentation (Fig. 5E). The $\mathrm{P}_{\mathrm{PT}}$ increased progressively in all groups until $40 \mathrm{~min}$ of furosemide infusion and remained elevated at $60 \mathrm{~min}$ (Fig. 5F).

\section{Discussion/Conclusion}

We confirm that an intravenous infusion of furosemide into rats reduces the GFR by $\sim 35 \%$ over $60 \mathrm{~min}$ [1]. The main new findings are that the progressive fall in GFR after furosemide is accompanied by a parallel reduction in RBF. There is a rise in urine output and a rise in $\mathrm{P}_{\mathrm{PT}}$ that peaks after 20-30 min. These renal hemodynamic changes are unaffected by volume repletion or by AT-1 receptor blockade, although losartan moderated the rise in RVR over this time because of a fall in MAP. The fall in GFR and RBF in this study with furosemide is similar to a ROMK inhibitor that also blocks $\mathrm{NaCl}$ reabsorption in the loop of Henle [1]. Thus, the renal hemodynamic response to furosemide can be ascribed to its renal tubular actions. The fall in GFR with furosemide infusion was prevented by bilateral renal deafferentation.

The changes in GFR during furosemide have been shown by micropuncture methods to represent complex interactions between mechanisms of vasoconstriction/vasorelaxation and physical forces caused by inhibition of tubular fluid reabsorption $[25,26]$ that cannot be deciphered unequivocally by clearance methods [6]. There was a tendency for the GFR and RBF measured by ${ }^{3} \mathrm{H}$ inulin and ${ }^{14} \mathrm{C} \mathrm{PAH}$ clearance to increase initially, but the RBF measured constantly during 20 min by a transit time flowmeter was reduced progressively within 5 min of starting the furosemide infusion. The abrupt increase in urine flow with furosemide likely 


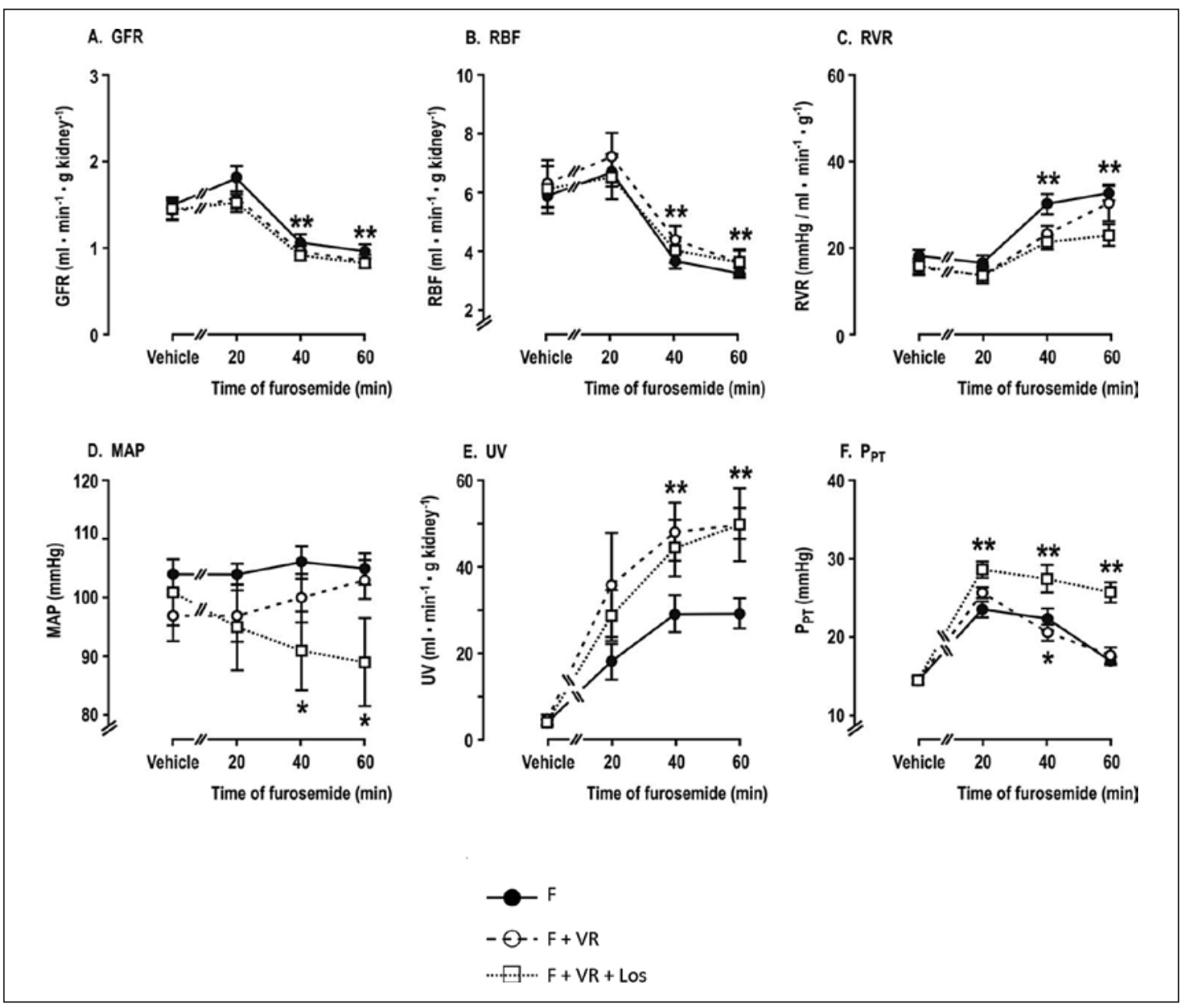

Fig. 3. Mean \pm SE absolute values for renal hemodynamics, mean arterial pressure, urine output, and proximal tubule pressure before (vehicle) and during $60 \mathrm{~min}$ of infusion of furosemide alone (solid circles and continuous lines, $n=8$ ), furosemide and volume replacement (open circles and dashed lines, $n=7$ ), and furosemide with volume replacement and losartan (open squares and dotted lines, $n=7$ ). Compared to each respective vehicle: ${ }^{*} p<0.05 ;{ }^{* *} p<0.01$

washed out filtered inulin and PAH that had been concentrated in tubular fluid that led to an artifactual early increase in the estimated GFR and RBF by clearance methods. A new steady state was achieved by 40-60 min. Therefore, the artefact should not influence the conclusions of this study.

The GFR of severely fluid-depleted rats infused with furosemide is maintained by a high efferent arteriolar resistance that is due to angiotensin since the glomerular capillary pressure $\left(\mathrm{P}_{\mathrm{GC}}\right)$ and the GFR collapse after angiotensin-converting enzyme inhibition [27].

However, careful restoration of fluid and $\mathrm{Na}^{+}$losses alone, or in combination with losartan, did not modify the fall in GFR with furosemide. Surprisingly, furosemide given without volume replacement did not increase the hematocrit, despite considerable diuresis. This may relate to its venodilating effect that can redistribute fluid into the blood stream [28]. There was indirect evidence that losartan reduced the efferent arteriolar resistance from a lesser increase in RVR and a fall in filtration fraction. Thus, activation of AT1Rs modulated the renal hemodynamic response to the loop diuretic but was not an essential component of the reduction in the GFR. 


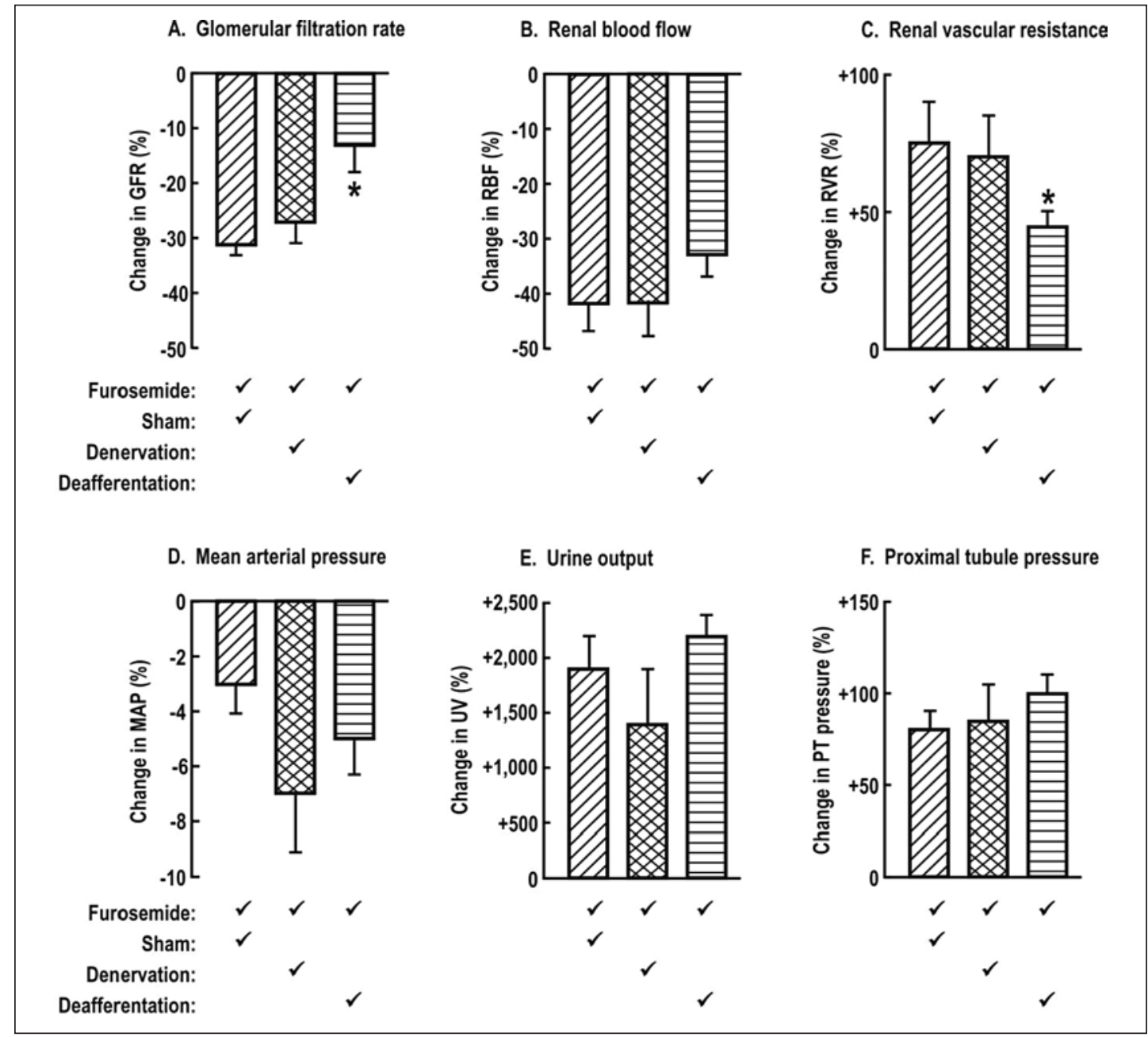

Fig. 4. Mean \pm SE values for fractional changes in renal hemodynamics, mean arterial pressure, urine output, and proximal tubule pressure before (vehicle) and after $60 \mathrm{~min}$ of a constant systemic infusion of furosemide with volume replacement 10 days after sham surgery (diagonal hatched bars, $n=6$ ), bilateral renal denervation (double crosshatched bars, $n=5$ ), or bilateral renal nerve deafferentation (horizontal lined bars, $n=8$ ). Compared to sham surgery: $* p<0.05$.

Prior studies with loop diuretics have disclosed some underlying mechanisms that affect renal hemodynamics. TGF vasoconstricts the renal afferent arterioles during increases in reabsorption of $\mathrm{Na}^{+}, \mathrm{K}^{+}$, and $\mathrm{Cl}^{-}$by NKCC2 in the macula densa cells. Furosemide blocks NKCC2 reabsorption and thereby blocks TGF. This occurs rapidly after furosemide is infused directly into the tubular lumen of the loop of Henle or infused intravenously into rats [1]. Therefore, inhibition of TGF by furosemide should dilate the renal afferent arterioles and increase the GFR and RBF. However, renal vasodilation was not detected by the constant, direct measurement of RBF during the first 20 min of furosemide (Fig. 1). Rather, other factors causing a progressive reduction in GFR and RBF and increase in RVR presumably overcame any effect of furosemide to block TGF.

The net glomerular ultrafiltration pressure in the rat outer cortical glomeruli averages only about $16 \mathrm{~mm} \mathrm{Hg}$, despite a glomerular capillary hydrostatic pressure of about $49 \mathrm{~mm}$ $\mathrm{Hg}$, because of the offsetting effects of the plasma protein oncotic pressure of about $15 \mathrm{~mm}$ $\mathrm{Hg}$ and the intratubular hydrostatic pressure of about $17 \mathrm{~mm} \mathrm{Hg}$ [29]. Accordingly, the 
Table 2. Heart rate, hematocrit, and filtration fraction of rats during infusion of vehicle (Veh) and during 20-min periods of intravenous infusion of F/VR 10 days after sham surgery (Sham), bilateral renal denervation, or deafferentation

\begin{tabular}{llll}
\hline & Sham & Denervation & Deafferentation \\
\hline Heart rate, bpm & & & \\
Veh & $319 \pm 14$ & $303 \pm 32$ & $332 \pm 14$ \\
$20 \mathrm{~min}$ & $319 \pm 13$ & $295 \pm 32$ & $332 \pm 14$ \\
$40 \mathrm{~min}$ & $319 \pm 13$ & $289 \pm 31$ & $330 \pm 13$ \\
$60 \mathrm{~min}$ & $321 \pm 13$ & $286 \pm 30$ & $326 \pm 14$ \\
\hline Hematocrit, \% & & & \\
Veh & $46 \pm 2$ & $45 \pm 1$ & $44 \pm 1$ \\
60 min & $45 \pm 2$ & $45 \pm 1$ & $45 \pm 1$ \\
\hline Filtration fraction & & & \\
Veh & $0.48 \pm 0.03$ & $0.52 \pm 0.03$ & $0.44 \pm 0.02$ \\
20 min & $0.53 \pm 0.05$ & $0.56 \pm 0.01$ & $0.48 \pm 0.02$ \\
40 min & $0.58 \pm 0.02$ & $0.62 \pm 0.04$ & $0.58 \pm 0.02^{*}$ \\
60 min & $0.62 \pm 0.03^{* *}$ & $0.68 \pm 0.03^{* *}$ & \\
\hline
\end{tabular}

Values are mean $\pm \mathrm{SE}(n=5$-8 pergroup). Veh, vehicle (before); F/VR, furosemide plus volume replacement; 20, 40, $60 \mathrm{~min}$, time into furosemide infusion. ${ }^{*} p<0.05$; ** $p<0.01 \mathrm{vs.} \mathrm{baseline} \mathrm{(Veh).}$

increase in $\mathrm{P}_{\mathrm{PT}}$ of $\sim 10 \mathrm{~mm} \mathrm{Hg}$ in the first 20 min of furosemide might have been expected to reduce the GFR profoundly. However, the rise in $\mathrm{P}_{\mathrm{PT}}$ after furosemide is matched by a similar rise in the intrarenal tissue pressure [30] that itself is matched by a rise in the glomerular capillary hydrostatic pressure $\left(\mathrm{P}_{\mathrm{GC}}\right)[25,26]$. A rise in intrarenal tissue pressure with furosemide [30] could collapse the peritubular capillaries and add to the flow resistance of the arterioles that would cause a passive rise in RVR. However, some of the increased RVR was apparently active vasoconstriction from angiotensin II since losartan moderated the progressive rise in RVR and reduced the FF, as previously reported [27].

Furosemide causes a sharp rise in the volume of the distal tubule of the rat, but the volume of the proximal tubule is maintained [31]. This may be explained because the proximal tubule is separated from the site of furosemide action in the loop of Henle by the thin loops of Henle that are the site of the maximum flow resistance in the nephron [32]. In contrast, the distal tubules have a low flow resistance, but likely develop a steep rise in pressure during increases in tubular fluid flow produced by furosemide because of a high flow resistance downstream in the collecting ducts [32]. An increase in resistance to flow through the nephron caused by increased fluid presentation to segments with high flow resistance presumably itself causes some reduction in clearance of glomerular filtrate. Thus, the increase in $\mathrm{P}_{\mathrm{PT}}$ during furosemide likely represents an increase in distal tubule volume and pressure, leading to a rise in renal interstitial pressure [30]. The return of $\mathrm{P}_{\mathrm{PT}}$ towards baseline, despite ongoing tubular effects of furosemide, may represent offsetting effects of reduced tubular filling from a sharply falling GFR $[33,34]$ and a reduction in the resistance of the renal capsule to stretch that moderates over time [35].

Furosemide activates renal efferent nerves in the rat [36-38] that would be anticipated to reduce the GFR, yet renal denervation does not prevent a reduction in GFR after furosemide in conscious lambs [39]. Furosemide also activates renal afferent nerves in anesthetized cats [40]. The sharp rise in $\mathrm{P}_{\mathrm{PT}}$ likely reflects an increase in intrapelvic pressure that activates renal afferent baroreceptors that also are limited to renal afferent nerves [41]. Indeed, increases in urine flow rate that raise the pelvic pressure by as little as $3 \mathrm{~mm} \mathrm{Hg}$ increase the rate of firing 


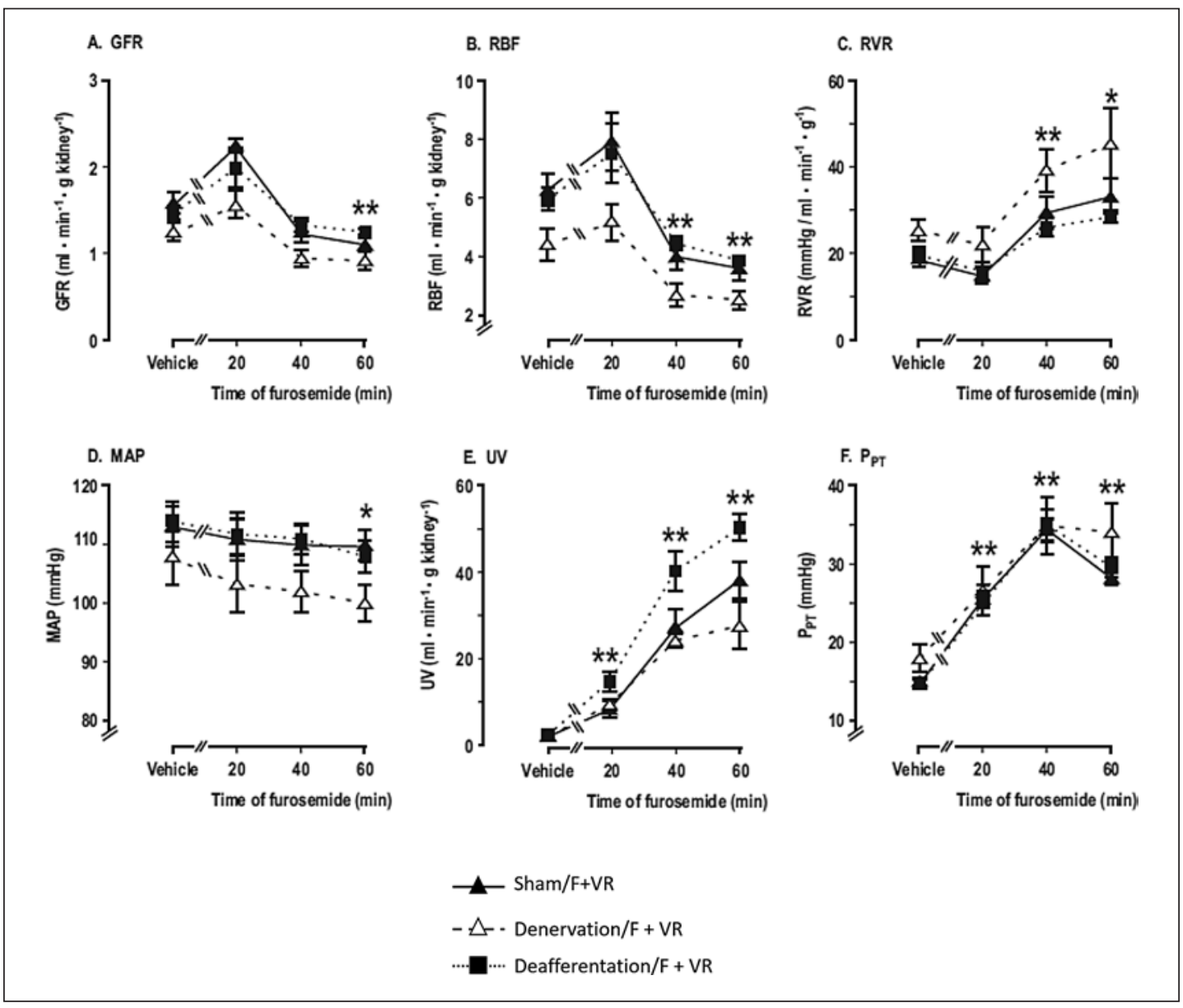

Fig. 5. Mean $\pm S E$ absolute values for renal hemodynamics, mean arterial pressure, urine output, and proximal tubule pressure before (vehicle) and during $60 \mathrm{~min}$ of infusion of furosemide with volume replacement 10 days after sham surgery (solid triangles and continuous lines, $n=6$ ), renal denervation (open triangles and dashed lines, $n=5$ ), or renal nerve deafferentation (solid squares and dotted lines, $n=8$ ). Compared to each respective vehicle: ${ }^{*} p<0.05 ;{ }^{* *} p<0.01$.

of the renal afferent nerve fibers [42]. Moreover, an increase in the urinary sodium concentration should stimulate the renal pelvic chemoreceptors. Thus, furosemide likely activated renal afferent nerves via chemoreceptors and/or baroreceptors in the kidneys [43, 44]. Furosemide increases the renal efferent sympathetic nerve discharge and reduces the GFR by $20 \%$. The finding that renal deafferentation blunted the fall in GFR with furosemide implicates the renal afferent nerves, but these studies leave unresolved what mediates this effect.

Stimuli that activate renal afferent nerves either acutely $[11,41-46]$ or over a prolonged period $[12,13,16,17]$, generally reflexly activate the renal efferent nerves, and this causes renal vasoconstriction and a fall in GFR. Accordingly, renal nerve deafferentation and renal nerve denervation were undertaken to assess the roles of renal innervation. Both maneuvers prevented a significant reduction in GFR with furosemide (Fig. 5A), but a puzzling finding was that only renal deafferentation prevented a reduction in the fractional fall in GFR (Fig. 4). Renal denervation depletes renin [47,48], blunts responses to nitric oxide [49] and adenosine $[50,51]$, and reduces the BP $[12,52]$, all of which may modulate the hemodynamic response. Renal denervation lowered the basal MAP, RBF, and GFR (Fig. 5). Loop diuretics block the TGF mechanism [1] and thereby impair renal autoregulation especially when the perfusion 
pressure is initially low and the range of myogenic relaxation is almost exhausted [53]. Thus, the fall in BP after renal denervation in these studies may have caused a fall in RBF and GFR with furosemide and thereby concealed an effect of the denervation procedure to maintain the GFR with furosemide. Therefore, the role of the renal efferent nerves in mediating the response to afferent nerve activation with furosemide in these studies remains unclear.

In conclusion, furosemide triggers an afferent renal nerve signal that causes renal vasoconstriction and a reduction in GFR by an unclear mechanism. A second, perhaps related, component of the fall in GFR is an increase in intrarenal pressure. However, the fall in GFR is not itself a consequence of a reduction in extracellular fluid volume or activation of AT1Rs.

\section{Perspective}

The present study suggests that selective pharmacological prevention of renal afferent nerve activation $[45,46]$ may be beneficial in preserving renal hemodynamics during furosemide treatment. The studies of Ulla Kopp and colleagues have shown the rich intrarenal regulation of renal afferent nerve activation [43] that entails endothelin-1 [45] and endothelin type A and B receptors [44, 46], angiotensin AT1 receptors [46], prostaglandins, adrenergic alpha- 1 and alpha- 2 receptors [42], and substance $P$ [41] that could be targets to relieve diuretic-induced azotemia or unwanted fluid retention. Our results also caution against routinely attributing rises in serum creatinine to furosemide-induced hypovolemia or activation of the RAS since furosemide caused major reductions in GFR despite volume replacement or losartan in this study.

\section{Acknowledgments}

C.S.W. is supported by the George E. Schreiner Chair of Nephrology, the Walters Family Chair of Cardiovascular Research, the Hypertension Center, and the Smith-Kogod Family Foundation.

\section{Statement of Ethics}

This study was conducted ethically in accordance with the World Medical Association Declaration of Helsinki. There were no human subjects involved in the research.

The procedures used to gather the data for the manuscript were approved and monitored by the Georgetown University Institutional Animal Care and Use Committee.

\section{Disclosure Statement}

C.S.W., W.J.W., M.A., and G.S. received salaries as employees of Georgetown University. C.S.W. and W.J.W. also received grant support as listed below.

Financial Support - Christopher S. Wilcox and William J. Welch

Current Grants

1 National Institutes of Health R0-1: "Regulation of Renal Function and BP by Thromboxane" (PI: C.S. Wilcox, R01-DK-109272).

2 National Institutes of Health: "Accelerated aging in microvessels and PVAT in women with HIV" (PI: C.S. Wilcox and D. Wang; R01-HL-134511-01). 


\section{Under Review}

1 National Institutes of Health Program Project Award RO-1: "Cerebral microarterioles resilience and dysfunction" (PI: C.S. Wilcox; HL14635).

2 National Institutes of Health RO-1: "Microvascular dysfunction in hypertension" (PI: C.S. Wilcox and W.J. Welch; HL-142608).

3 National Institutes of Health R0-1: "Hypertensive impairment of vasoconstrictor resilience and myogenic mechanisms in cerebral microarterioles" (PI: C.S. Wilcox and W.J. Welch).

4 National Institutes of Health Research Project Grant RO-1 HL1479511: "Microvascular senescence in hypertension and aging" (PI: C.S. Wilcox and W.J. Welch; R01 HL 147951-01).

5 National Institutes of Health R44 HL147647: "Torsemide ER comparison with torsemide IR and furosemide for management of heart failure" (Scientific PI: C.S. Wilcox).

6 National Institutes of Health R44DK098856: "Extended Release Torsemide: Phase 2B" (Scientific PI: C.S. Wilcox).

All forms of support and financial involvement (e.g., employment, consultancies, honoraria, stock ownership and options, expert testimony, grants or patents received or pending, royalties) which took place in the previous 3 years are listed, regardless of their potential relevance to the paper.

There are no nonfinancial relationships (personal, political, or professional) that may potentially influence the writing of the manuscript.

The authors have no conflict of interest to declare.

\section{Funding Sources}

C.S.W. received local funding. He is supported by the George E Schreiner Chair of Nephrology, the Hypertension Center, and the Smith-Kogod Family Foundation. None of these sources of support played any role in the preparation of data or the manuscript. There were no funding sources for this study that was supported by institutional funds.

\section{Author Contributions}

M.A., C.S.W., W.J.W. designed the study. M.A. performed all GFR/micropuncture experiments and the denervation/deafferentation surgeries. G.S. performed the short-term RBF experiments. M.A. analyzed the data and prepared figures and tables. M.A., W.J.W., and C.S.W. contributed to the interpretation of the results. M.A. wrote the first draft of the manuscript. C.S.W. wrote the protocol and the final drafts of the manuscript.

\section{References}

1 Araujo M, Welch WJ, Zhou X, Sullivan K, Walsh S, Pasternak A, et al. Inhibition of ROMK blocks macula densa tubuloglomerular feedback yet causes renal vasoconstriction in anesthetized rats. Am J Physiol Renal Physiol. 2017 Jun;312(6):F1120-7.

2 Almeshari K, Ahlstrom NG, Capraro FE, Wilcox CS. A volume-independent component to postdiuretic sodium retention in humans. J Am Soc Nephrol. 1993 Jun;3(12):1878-83.

3 Kelly RA, Wilcox CS, Mitch WE, Meyer TW, Souney PF, Rayment CM, et al. Response of the kidney to furosemide. II. Effect of captopril on sodium balance. Kidney Int. 1983 Aug;24(2):233-9.

4 Wilcox CS, Guzman NJ, Mitch WE, Kelly RA, Maroni BJ, Souney PF, et al. Na+, K+, and BP homeostasis in man during furosemide: effects of prazosin and captopril. Kidney Int. 1987 Jan;31(1):135-41.

5 Wilcox CS, Mitch WE, Kelly RA, Skorecki K, Meyer TW, Friedman PA, et al. Response of the kidney to furosemide. I. Effects of salt intake and renal compensation. J Lab Clin Med. 1983 Sep;102(3):450-8. 
Araujo et al.: Furosemide and GFR

6 Huang X, Dorhout Mees E, Vos P, Hamza S, Braam B. Everything we always wanted to know about furosemide but were afraid to ask. Am J Physiol Renal Physiol. 2016 May;310(10):F958-71.

7 Beldhuis IE, Streng KW, Ter Maaten JM, Voors AA, van der Meer P, Rossignol P, et al. Renin-Angiotensin System Inhibition, Worsening Renal Function, and Outcome in Heart Failure Patients With Reduced and Preserved Ejection Fraction: A Meta-Analysis of Published Study Data. Circ Heart Fail. 2017 Feb;10(2):e003588.

8 Oppermann M, Hansen PB, Castrop H, Schnermann J. Vasodilatation of afferent arterioles and paradoxical increase of renal vascular resistance by furosemide in mice. Am J Physiol Renal Physiol. 2007 Jul;293(1):F27987.

9 Cao W, Shi M, Wu L, Yang Z, Yang X, Liu H, et al. A renal-cerebral-peripheral sympathetic reflex mediates insulin resistance in chronic kidney disease. EBioMedicine. 2018 Nov;37:281-93.

10 DiBona GF. CS. The kidney and the sympathetic nervous system. Autonom Fail. 1999;4:143-50.

11 Johns EJ, Kopp UC, DiBona GF. Neural control of renal function. Compr Physiol. 2011 Apr;1(2):731-67.

12 Osborn JW, Foss JD. Renal Nerves and Long-Term Control of Arterial Pressure. Compr Physiol. 2017 Mar; 7(2): 263-320.

13 Cao W, Li A, Li J, Wu C, Cui S, Zhou Z, et al. Reno-Cerebral Reflex Activates the Renin-Angiotensin System, Promoting Oxidative Stress and Renal Damage After Ischemia-Reperfusion Injury. Antioxid Redox Signal. 2017;27(7):415-32.

14 DiBona GF. Sympathetic nervous system and hypertension. Hypertension. 2013;61(3):556-60.

15 Banek CT, Gauthier MM, Baumann DC, Van Helden D, Asirvatham-Jeyaraj N, Panoskaltsis-Mortari A, et al. Targeted afferent renal denervation reduces arterial pressure but not renal inflammation in established DOCA-salt hypertension in the rat. Am J Physiol Regul Integr Comp Physiol. 2018 Jun;314(6):R883-91.

16 Cao W, Li A, Wang L, Zhou Z, Su Z, Bin W, et al. A Salt-Induced Reno-Cerebral Reflex Activates Renin-Angiotensin Systems and Promotes CKD Progression. J Am Soc Nephrol. 2015 Jul;26(7):1619-33.

17 Converse RL Jr, Jacobsen TN, Toto RD, Jost CM, Cosentino F, Fouad-Tarazi F, et al. Sympathetic overactivity in patients with chronic renal failure. N Engl J Med. 1992 Dec;327(27):1912-8.

18 DiBona GF, Sawin LL. Renal nerve activity in conscious rats during volume expansion and depletion. Am J Physiol. 1985 Jan;248(1 Pt 2):F15-23.

19 Wang Y, Chen AF, Wang DH. Enhanced oxidative stress in kidneys of salt-sensitive hypertension: role of sensory nerves. Am J Physiol Heart Circ Physiol. 2006 Dec;291(6):H3136-43.

20 Loon NR, Wilcox CS, Unwin RJ. Mechanism of impaired natriuretic response to furosemide during prolonged therapy. Kidney Int. 1989 Oct;36(4):682-9.

21 Welch WJ, Wilcox CS. Potentiation of tubuloglomerular feedback in the rat by thromboxane mimetic. Role of macula densa. J Clin Invest. 1992 Jun;89(6):1857-65.

22 Welch WJ, Deng X, Snellen H, Wilcox CS. Validation of miniature ultrasonic transit-time flow probes for measurement of renal blood flow in rats. Am J Physiol. 1995 Jan;268(1 Pt 2):F175-8.

23 Foss JD, Wainford RD, Engeland WC, Fink GD, Osborn JW. A novel method of selective ablation of afferent renal nerves by periaxonal application of capsaicin. Am J Physiol Regul Integr Comp Physiol. 2015 Jan;308(2):R112-22.

24 Jacob F, Clark LA, Guzman PA, Osborn JW. Role of renal nerves in development of hypertension in DOCA-salt model in rats: a telemetric approach. Am J Physiol Heart Circ Physiol. 2005 Oct;289(4):H1519-29.

25 Lane PH, Tyler LD, Schmitz PG. Chronic administration of furosemide augments renal weight and glomerular capillary pressure in normal rats. Am J Physiol. 1998 Aug;275(2):F230-4.

26 Burke TJ, Duchin KL. Glomerular filtration during furosemide diuresis in the dog. Kidney Int. 1979 Dec;16(6): 672-80.

27 Kon V, Fogo A, Ichikawa I, Hellings SE, Bills T. Bradykinin causes selective efferent arteriolar dilation during angiotensin I converting enzyme inhibition. Kidney Int. 1993 Sep;44(3):545-50.

28 Dikshit K, Vyden JK, Forrester JS, Chatterjee K, Prakash R, Swan HJ. Renal and extrarenal hemodynamic effects of furosemide in congestive heart failure after acute myocardial infarction. N Engl J Med. 1973 May;288(21): 1087-90.

29 Baylis C, Ichikawa I, Willis WT, Wilson CB, Brenner BM. Dynamics of glomerular ultrafiltration. IX. Effects of plasma protein concentration. Am J Physiol. 1977 Jan;232(1):F58-71.

30 Johnsson E, Rippe B, Haraldsson B. Analysis of the pressure-flow characteristics of isolated perfused rat kidneys with inhibited tubular reabsorption. Acta Physiol Scand. 1994 Feb;150(2):189-99.

31 Simeoni M, Boyde A, Shirley DG, Capasso G, Unwin RJ. Application of red laser video-rate scanning confocal microscopy to in vivo assessment of tubular function in the rat: selective action of diuretics on tubular diameter. Exp Physiol. 2004 Mar;89(2):181-5.

32 Gilmer GG, Deshpande VG, Chou CL, Knepper M. Flow resistance along the rat renal tubule. Am J Physiol Renal Physiol. 2018 Nov;315(5):F1398-405.

33 Persson P, Hansell P, Palm F. Tubular reabsorption and diabetes-induced glomerular hyperfiltration. Acta Physiol (Oxf). 2010 Sep;200(1):3-10.

34 Karlsen FM, Holstein-Rathlou NH, Leyssac PP. A re-evaluation of the determinants of glomerular filtration rate. Acta Physiol Scand. 1995 Dec;155(4):335-50.

35 Herbert LA, Chen WC, Hartmann A, Garancis JC. Mechanical properties of the dog renal capsule. J Appl Physiol. 1976 Feb;40(2):164-70.

36 Baranova AF, Nozdrachev AD, Chernigovskiu VN. [Afferent activity in the renal nerves of awake dogs treated with diuretics]. Fiziol Zh SSSR Im I M Sechenova. 1975 Nov;61(11):1657-63. 
37 Fitch GK, Patel KP, Weiss ML. Activation of renal afferent pathways following furosemide treatment. I. Effects Of survival time and renal denervation. Brain Res. 2000 Apr;861(2):363-76.

38 Fitch GK, Weiss ML. Activation of renal afferent pathways following furosemide treatment. II. Effect Of angiotensin blockade. Brain Res. 2000 Apr;861(2):377-89.

39 Smith FG, Strack AM, de Wildt SN. Renal nerves do not modulate the renal and endocrine responses to furosemide in conscious lambs. Can J Physiol Pharmacol. 1996 May;74(5):614-20.

40 Genovesi S, Pieruzzi F, Wijnmaalen P, Centonza L, Golin R, Zanchetti A, et al. Renal afferents signaling diuretic activity in the cat. Circ Res. 1993 Nov;73(5):906-13.

41 Kopp UC, Smith LA. Inhibitory renorenal reflexes: a role for substance P or other capsaicin-sensitive neurons. Am J Physiol. 1991 Jan;260(1 Pt 2):R232-9.

42 Kopp UC, Cicha MZ, Smith LA, Mulder J, Hökfelt T. Renal sympathetic nerve activity modulates afferent renal nerve activity by PGE2-dependent activation of alpha1- and alpha2-adrenoceptors on renal sensory nerve fibers. Am J Physiol Regul Integr Comp Physiol. 2007 Oct;293(4):R1561-72.

43 Kopp UC. Role of renal sensory nerves in physiological and pathophysiological conditions. Am J Physiol Regul Integr Comp Physiol. 2015 Jan;308(2):R79-95.

44 Kopp UC, Cicha MZ, Jones SY. Activation of endothelin A receptors contributes to impaired responsiveness of renal mechanosensory nerves in congestive heart failure. Can J Physiol Pharmacol. 2010 Jun;88(6):622-9.

45 Kopp UC. Endothelin in the control of renal sympathetic nerve activity. Contrib Nephrol. 2011;172:107-19.

46 Kopp UC, Cicha MZ, Smith LA. Activation of endothelin-a receptors contributes to angiotensin-induced suppression of renal sensory nerve activation. Hypertension. 2007;49(1):141-7.

47 Ito H, Wang J, Strandhoy JW, Rose JC. Importance of the renal nerves for basal and stimulated renin mRNA levels in fetal and adult ovine kidneys. J Soc Gynecol Investig. 2001 Nov-Dec;8(6):327-33.

48 Taquini AC, Fasciolo JC, Fernandez Luna D. [Site of formation of renin in the kidney]. Medicina (B Aires). 1950 Jun;10(3):174-7.

49 Gabbai FB, Thomson SC, Peterson 0, Wead L, Malvey K, Blantz RC. Glomerular and tubular interactions between renal adrenergic activity and nitric oxide. Am J Physiol. 1995 Jun;268(6 Pt 2):F1004-8.

50 Girchev R, Mikhov D, Markova P. Renal and cardiovascular effects of renal denervation in conscious rats after adenosine administration and nitric oxide synthase inhibition. Kidney Blood Press Res. 2002;25(4):217-23.

51 Fransen R, Koomans HA. Adenosine and renal sodium handling: direct natriuresis and renal nerve-mediated antinatriuresis. J Am Soc Nephrol. 1995 Nov;6(5):1491-7.

52 Alsheikh AJ, Lund H, Dasinger JH, Abais-Battad JM, Fehrenbach DJ, Mattson DL. Renal nerves and leukocyte infiltration in the kidney during salt-sensitive hypertension. Am J Physiol Regul Integr Comp Physiol. 2019 Jul; 317(1):R182-9.

53 Carlström M, Wilcox CS, Arendshorst WJ. Renal autoregulation in health and disease. Physiol Rev. 2015 Apr; 95(2):405-511. 